\title{
Boccaccio y Cervantes: posibles fuentes italianas de La cueva de Salamanca ${ }^{1}$
}

\section{María Hernández Esteban}

Universidad Complutense de Madrid

mariaher@filol.ucm.es

\begin{abstract}
A partir del Decameron como arquetipo narrativo, sugiero delimitar un «corpus» de relatos sobre el empleo de la magia en la burla matrimonial para enfocar motivos, personajes-tipo, técnicas compositivas y recursos expresivos que, desde el libro de Boccaccio, la narrativa y el teatro del Renacimiento difundieron a nuestra literatura. Se pretende con ello replantear el tema de las fuentes italianas del entremés La cueva de Salamanca para valorar mejor, también desde posibles modelos italianos, la profunda innovación del texto cervantino y el trasfondo ideológico que la anima.
\end{abstract}

Palabras clave: Decameron, La cueva de Salamanca, magia, adulterio, sistemas comparativos, evolución literaria.

\section{Abstract}

From considering the Decameron a narrative archetype, I suggest setting up the boundaries of a corpus of accounts about the use of magics in the marriage mockery in order to focus on motives, characters, types, composition techniques and expressive resources which, from the book written by Boccaccio, the narrative and the drama of the Renaissance spread in our literature. The purpose of this is to reopen once again the theme of the Italian sources in the entremés La cueva de Salamanca in order to better improve - even from possible Italian models_-, the deep innovation of the Cervantes' text and the ideological background behind it.

Key words: Decameron, La cueva de Salamanca, magics, adultery, comparative systems, literary development.

1. Este trabajo se inscribe dentro del Proyecto de Investigación I+D con referencia HUM200502635/FILO del cual soy investigadora principal. 


\section{Los hilos para tejer la «tela»}

Cervantes, como anteriormente Boccaccio, fue tejiendo con sus fuentes un diálogo muy elaborado y personal; Anthony Close subraya, «su deslumbrante poder de asimilación y de síntesis», «su prodigiosa capacidad para articular, entretejer y [...] parodiar registros y contextos literarios», su «delirante eclecticismo». ${ }^{2}$

Con pocas excepciones, como la de Garcilaso, de quien engasta citas con admiración y respeto, su innovación se nutre también del sistema de mezcla de materiales de distinto origen, que reelabora y transforma con gran libertad, con fines a menudo paródicos, controlando los hilos que maneja, ocultando o desvelando su juego. En La cueva de Salamanca se ha hablado de una auténtica "polifonía textual». ${ }^{3}$

El sistema cervantino recuerda, salvando las distancias, a la técnica del "mescolato" y a la complejísima taracea de fuentes que Boccaccio fue fabricando continuamentre, acumulando e invirtiendo materiales dispares, con una apertura y flexibilidad que hace casi imposible agotar la localización de su origen, como la crítica viene demostrando. ${ }^{4}$ Su intención expresiva se haría patente: al acudir, por ejemplo, a fuentes piadosas y someterlas a un enérgico proceso de inversión, se llega a la parodia.

En la producción cervantina, sólo tal vez en La Galatea se vislumbran algunas fuentes con una cierta claridad, siguiendo las premisas de un género donde lo que procedía era imitar y reutilizar abiertamente los materiales literarios, afianzando un sistema de prosa muy específico.

En una línea expresiva casi opuesta, los entremeses asumen, además, la libertad propia del registro cómico, donde ya el propio ensamblaje de materiales de diverso origen provoca la parodia, a los ojos, sobre todo, del receptor coetáneo capaz de reconocer la procedencia de los mismos, desentrañar el juego del escritor y valorar la subversión. No hay que descartar, además, la mezcla y la ocultación como estrategias añadidas frente a la censura.

En un trabajo anterior he intentado demostrar que Cervantes pudo utilizar fuentes decameronianas precisas para un pasaje emblemático de La Galatea. ${ }^{5}$

2. Anthony Close, prólogo a la ed. de Don Quijote, Madrid: Galaxia, 2004, p. LXXX.

3. Catalina BuEzo, "La magia al servicio de la burla entremesil: el estudiante de La cueva de Salamanca». Anthropos, 154-155, 1994, p. 115-118, p. 117. A este breve estudio de Buezo que tiene también en cuenta las fuentes folclóricas, añado ahora en pruebas un interesante trabajo de José Manuel Pedrosa con sólidas aportaciones y conclusiones coincidentes con la tesis de estas páginas. Cfr. "El conjuro de la adúltera (AT1419H): del cuento y la canción orales a la tradición escrita (entre Boccaccio, Timoneda, Cervantes y Lorca)", en Formas narrativas breves en la Edad Media. Actas del IV Congreso, Santiago de Compostela 8-10 de julio de 2004, coordinador E. Fidalgo, Santiago de Compostela, Universidad, 2005, p. 123-148.

4. Cfr. «Decameron ipertestuale» http:www.rose.unizh.ch/decameron, o la reciente publicación: Michelangelo PICONE (a cura di), Autori e lettori del Boccaccio, Firenze: Franco Cesati Editore, 2002; también Michelangelo PiCONE e Margherita MesirCA(a cura di), Lettura del «Decameron» Firenze: Franco Cesati Editore, 2004 con materiales novedosos.

5. María Hernández EstebAn, «Cervantes, lettore del Boccaccio? La cornice del Decameron modello di un episodio della Galatea» Rivista di Filologia e Letterature ispaniche, X, 2007, p. 41-61. 
Una hipótesis estimulante, apoyada en el cotejo de textos concretos para señalar recurrencias textuales precisas, practicando un comparatismo filológico y textual, que en este caso no es posible aplicar.

En estas páginas, aún persiguiendo un objetivo análogo que refuerce además las conclusiones precedentes, sugiero un distinto sistema comparativo: partir del Decameron como arquetipo narrativo y delimitar algunos de los motivos argumentales, esquemas narrativos, personajes-tipo y técnicas constructivas que Boccaccio fijó en su libro y puso a disposición de la cuentística y del teatro renacentistas, abonando una tradición con la que Cervantes pudo dialogar.

\section{El registro cómico}

En la trayectoria cervantina, a partir sobre todo de 1606, se reaviva el interés hacia el registro cómico, desde el denso ejercicio del Quijote hasta la hilarante parodia del mundo literario que encierra el Viaje del Parnaso (1614) con mecanismos afines a los del singular espacio cómico que forman sus ocho entremeses, redactados entre 1609 y $1615 .^{6}$

En esa intensa etapa de trabajo se consolida su maestría en el arte de la comicidad; para filtrar la denuncia de situaciones sociales, familiares e intelectuales injustas acude a la parodia, la burla, la desmitificación.

En un entorno ideológico y social represivo y hostil, «con estamentos tan rígidos como el código del honor, la institución del matrimonio o la moral cristiana ${ }^{7}$ los entremeses le permitieron cuestionar la validez de esos estamentos, como se verá al final de La cueva de Salamanca.

Sobre las muchas deudas de Cervantes con la literatura escrita él mismo confiesa su avidez lectora casi patológica, demostrando su acceso a una cultura literaria muy amplia, ${ }^{8}$ y su almacenar materiales en una memoria acumulativa excepcional.

$\mathrm{Al}$ experimentar con las formas dramáticas, frente al mundo idealizado de la comedia, el entremés enfoca el mundo cómico y «entra a saco en los géneros populares», adoptando los modos de enfoque, la tonalidad del diálogo, los sistemas de lo popular, ${ }^{9}$ en contacto con un acervo folclórico y un mundo de costumbres y tradiciones populares amalgamados en los entremeses, y en $\mathrm{La}$ cueva de Salamanca en especial.

En esa "polifonía» de materiales sobre la que se asienta la construcción de estas piezas, puede ser útil replantear la incidencia de la tradición narrativa y tea-

6. Miguel de Cervantes, Entremeses, ed. Eugenio Asensio, Madrid: Castalia, 1970, p. 16 del «Prólogo». También, la «Introducción» de Antonio ReY HaZAS a los Entremeses, Madrid, Alianza, 2006, por la que citaré siempre.

7. Vicente PÉREZ DE LEÓN, Tablas destempladas. Los entremeses de Cervantes a examen, Alcalá de Henares: Centro de Estudios Cervantinos, 2005, p. 118.

8. «y como yo soy aficionado a leer, aunque sean los papeles rotos de las calles, llevado desta mi natural inclinación tomé un cartapacio..." Don Quijote de la Mancha, ed. De Martín de RiQuer, Barcelona: Planeta, 1975, I, 9, p. 100-101.

9. Eugenio ASENSIO, «Prólogo» Entremeses, cit., p. 19. 
tral de origen italiano. Los eficaces mecanismos que Boccaccio puso a funcionar para activar la ironía y la parodia en su gran libro, auténtica enciclopedia de modos, técnicas y sistemas expresivos, no podían dejar insensible a un escritor con la capacidad inventiva y cómica de Cervantes.

\section{Algunas fuentes señaladas para el entremés}

Frente a la ya lejana caza de una fuente aproximativa para explicar el origen del argumento, hoy se valora el proceso de superposición de fuentes de procedencia dispar; la innovación cervantina le debe mucho al procedimiento de acumulación, que adquiere significado propio y activa la comicidad. La inversión de modelos filtra con sutileza la carga ideológica que subyace en el texto.

Sobre las posibles deudas con la tradición italiana, la crítica ha hecho sugerencias imprecisas y ha transmitido errores en cadena, con datos sin verificar. Puede ser útil replantear esta línea de trabajo para enfocar también desde esa perspectiva algunos recursos cómicos cervantinos, algunas de sus estrategias compositivas y expresivas; la inversión y la transformación de materiales, analizados desde una atenta lectura del libro de Boccaccio, pueden sugerir reflexiones sobre la evolución de los géneros y el devenir de las ideas.

Para desentrañar la construcción de este magnífico entremés se ha señalado ya un amplio catálogo de referencias tanto literarias como folclóricas, globales o precisas, peninsulares o europeas.

Entre las fuentes concretas indicadas, Eugenio Asensio señaló las llamativas semejanzas con la farsa carnavalesca de Hans Sachs El escolar andariego y el conjuro del diablo, de 1551, que pudo llegar a Cervantes desde una fuente folclórica común. ${ }^{10}$ Además, Asensio no descarta que detrás de la construcción del entremés esté también el recuerdo de la técnica de las «novelle».

Un claro panorama reciente de los hilos temáticos y constructivos que conectarían al entremés con una muy amplia tradición lo ofrece Catalina Buezo, al señalar:

1. dos motivos folclóricos que se mezclan en el relato de la malcasada, el tipo 1358 C y el 1358 A del catálogo de Aarne-Thompson;

2. el esquema del cuento maravilloso, aplicable a la trama del entremés, como ella propone en su trabajo;

3. la leyenda local de la cueva;

4. la práctica de las procesiones carnavalescas y de las comitivas profanas del Corpus Christi, con la presencia de diablos;

5. los romances;

6. la letra de una danza de sacristanes;

7. el conjuro parodiado del Laberinto de Juan de Mena.

Hay que añadir que algunas de las fuentes italianas que han sido ya señaladas, o son imprecisas, o desconcertantes. 
En el caso de las primeras, han quedado sin delimitar los motivos coincidentes que indicó Giannini, traductor de los entremeses al italiano en 1915, remitiendo $^{11}$ a Decameron, VII.2, donde se cuenta la aventura de Peronella. A dichos motivos y situaciones aludiré después, cotejando los pasajes coincidentes.

Entre las fuentes desconcertantes están Bandello y Timoneda. Desde el trabajo de William L. Fichter de 1960 se viene señalando como antecedente el relato I,35 de Bandello ( Nuovo modo di castigar la moglie ritrovato da un gentiluomo veneziano»); el único hilo de conexión que se aduce es la coincidencia del nombre de los maridos, Pancracio y messer Pancrati Giustiniano; además, los motivos más llamativos del cuento de Bandello, como el escatológico, no se reflejan en el texto de Cervantes. ${ }^{12}$ Tal propuesta, no obstante, se sigue citando en la bibliografía específica de ensayos y ediciones, con escasas refutaciones, como la de Stanislav Zimic, ${ }^{13}$ que la encuentra "poco persuasiva».

En cuanto a la deuda señalada con Timoneda, (que no es italiano, pero difunde argumentos de origen italiano muy diverso) varios editores demuestran no haber cotejado el dato que remite a la $\mathrm{X}^{\mathrm{a}}$ patraña. Spadaccini remite tanto al cuento de Bandello como a la patraña ${ }^{14}$ X de Timoneda. ${ }^{15}$

Puede ser útil volver al marco de las alusiones globales a los "personajes, tramas, conclusiones que parecen haber estado inspirados en episodios de novellas (sic.) italianas o de anécdotas de novelas picarescas, llevadas a las tablas, aderezadas con multitud de recursos escénicos del teatro italiano de la commedia dell'arte». ${ }^{16}$ En esta dirección el cotejo de textos, procedimientos e ideologías puede enriquecer la lectura del texto cervantino.

\section{Materiales decameronianos}

Desde el arquetipo narrativo boccacciano, sugiero delimitar un corpus de referencia formado por los siguientes cuentos:

1. VII.1, VII.2 y VII.3 para la situación de adulterio con la repentina presencia del marido; en dos casos se acude al remedio excepcional de la magia;

2. II.9,27 para el motivo del lunar en el pecho;

3. VIII.7 para la actuación del estudiante que dice haber estudiado en París y haber aprendido magia;

11. Miguel de Cervantes, Gl'Intermezzi. Tradotti ed illustrati da Alfredo Giannini, Lanciano: R. Carabba, 1915.

12. William L. Fichter, "La cueva de Salamanca, de Cervantes y un cuento de Bandello», en Homenaje a Dámaso Alonso. Studia hispánica, I, p. 527-528.

13. Stanislav ZIMIC, "La cueva de Salamanca, parábola de la tontería", Anales cervantinos, XX, p. 145 , n. 28.

14. Cfr. en cambio las muy precisas notas de José Romera Castillo, Joan Timoneda, El Patrañuelo, Madrid: Cátedra, 1986, p. 192, donde se delimita bien el posible recorrido del argumento.

15. Cfr. Miguel de Cervantes, Entremeses, Madrid: Cátedra, 1998, p. 37, n. 34

16. Vicente PÉreZ de LeÓn, Tablas destempladas. Los entremeses de Cervantes a examen, op. cit., p. 69. 
4. IV.2,26 ss. para el paródico juego cuerpo/alma del supuesto arcángel san Gabriel;

5. además, recuerdo que en el libro se insiste en el binomio comida y sexo en II.2, III.4, V.10, VII.1 y VIII.10.

Por último, enumero más adelante en nota los doce cuentos donde se practica algún tipo de magia como eficaz medio de engaño.

Este conjunto de relatos habrían difundido unos materiales que, de manera directa o indirecta, desde Boccaccio o desde fuentes interpuestas, podrían formar parte de los elementos compositivos que conforman tanto la trama de La cueva de Salamanca como el registro cómico de otras piezas teatrales del escritor.

\section{Notas sobre el género del entremés}

Para ubicar el texto en sus coordenadas literarias, estudios como el de García Blanco se remontan a los mimos griegos, a las farsas atelanas, a los juegos de escarnio medievales, hasta llegar al teatro de Lope de Rueda, y a las farsas renacentistas. Cervantes, no podía ignorar, además, la práctica teatral italiana posterior de Machiavelli, Ariosto o Aretino, herederos directos del modelo decameroniano. Por último, se han señalado también las deudas con las técnicas escénicas de la commedia dell'arte, sus tipos, y su gusto por la farsa y la confusión.

Los entremeses cervantinos enfocan un mundo marginal, que no había tenido cabida ni en sus novelas ejemplares, ni en las comedias; como Eugenio Asensio ha señalado, el público implícito de estas piezas teatrales quería ver parodiado en ellas lo que no admitiría en las comedias.

El modelo vertebral de Lope de Rueda es determinante; los entremeses, como los "pasos», «explotan con éxito toda una gama de comportamientos cómicos encarnados por tipos fijados por la tradición» para enfocar el engaño, la astucia, la necedad, la desvergüenza, etc. «Situaciones codificadas — señala Canavaggio - pero que recuperan su frescor gracias a los recursos de un lenguaje expresivo apto para recrear la vida». ${ }^{17}$

\section{Motivos y personajes de La cueva de Salamanca}

\subsection{El empleo de la magia}

- En el Decameron. En ocho de los doce cuentos en los que se practica la magia con fines burlescos, ésta resulta el medio más rotundo para engañar y humillar a los personajes más ignorantes, a los que se castiga por su perniciosa necedad. ${ }^{18}$ En un libro que exalta la inteligencia en cada uno de

17. Jean Canavaggio, Cervantes, Madrid: Espasa Calpe, 2003, p. 367-370.

18. III,8 (Ferondo); IV,2 (frate Alberto); VII,1 (Gianni Lotteringhi); VII,3 (frate Rinaldo); VIII,3 (Calandrino y la helitropía); VII.9 (Lidia y Nicóstrato); VIII,6 (Calandrino robado); VIII,7 (el escolar y la viuda); VIII.9 (Simone, Bruno y Buffalmacco); IX,5 (Calandrino enamorado); IX,3 (Calandrino preñado); IX,10 (don Gianni). 
sus cuentos y en el simbolismo de su estructura general, enfocar la cortedad mental no es sólo un medio seguro para la burla y la diversión, sino que desvela cómo las limitaciones humanas pueden también dañar la convivencia y, en este caso, los derechos de la mujer.

En VII.1 la malcasada se vuelve infiel, y acude a la magia en una situación muy comprometida. Supuesta magia y sexo comparten un mismo escenario de actuación. Considerar la trama y técnicas de este relato puede ser útil para replantear las fuentes que aquí voy a proponer.

En VII.3, ante la llegada improvisa del marido, es la mujer quien le explica que frate Rinaldo está con ella encantando a las lombrices para curar a su hijito. La cercanía de ambos cuentos, y la coincidencia en la situación, móviles y fines, activan un mecanismo de refuerzo para fijar sus motivos clave en la memoria del lector.

En tres cuentos del libro (III.8, IV.2 y IX.10) es un religioso quien utiliza la magia como pretexto para satisfacer su deseo sexual, con distintos procedimientos: el abad engaña a Ferondo metiéndole en el purgatorio, frate Alberto se finge el arcángel san Gabriel para «visitar» a doña Lisetta y donno Gianni dice que va a encantar a la yegua del compadre Piero para intentar poseer a su mujer.

Los cuentos VIII.3, VIII.6, IX.3 y IX.5 forman una serie excepcional, donde el protagonista es siempre el necio Calandrino, y son sus amigos quienes planean engañar al más simple e infeliz de todos los personajes del libro, con cuatro burlas de magia a cual más ingeniosa. Queda claro, al insistir en el mismo personaje, que sólo un gran necio como Calandrino se deja engañar por lo inverosímil e irracional; la burla se hace acumulativa, hiperbólica y excepcional. Estos cuatro relatos refuerzan de forma implícita la necedad de los maridos que, como Calandrino, se dejan engañar por la magia sin rechistar.

Boccaccio, buen lector de Apuleyo, maneja la magia, ${ }^{19}$ como arma de castigo contra la superstición, o contra la beatería de algunos maridos, o como el mejor medio de castigar al ignorante. En el libro se deja entrever un rechazo hacia la necedad que sobrepasa incluso a la simpatía hacia el despliegue de astucia de quien urde la burla.

También el teatro renacentista acude a la magia como un medio excepcional para la comicidad y la denuncia social. Baste citar el rotundo ejemplo de La mandragola, de Machiavelli, donde se involucra en la tremenda burla a todos los personajes de la comedia, con una denuncia amarga de profundo calado social.

- En los entremeses cervantinos. Cervantes emplea la magia como instrumento del engaño en dos de sus entremeses: El retablo de las maravillas y La cueva de Salamanca, dos textos que hunden sus raíces en el folclore y en las tradiciones populares autóctonas, sin olvidar referentes literarios de la cuentística, como el Conde Lucanor de don Juan Manuel, cuento XXXII, 
antecedente para el motivo del retablo maravilloso, o los muy diversos materiales ya citados de diferente origen. En ambos casos el escritor encuentra en la magia, además del legado de significados que le ha transmitido la tradición, un medio idóneo para replantear conflictos sociales e ideológicos muy candentes en su época, sofocados por los estamentos del poder.

\subsection{Los personajes-tipo y su evolución}

En el teatro el enfrentamiento tradicional mujer - marido - amante se complica para animar el escenario y enredar la trama. Enumero los siete personajes de La cueva de Salamanca:

- Pancracio, el marido;

- Leonarda, la mujer;

- Reponce, el sacristán, amante de Leonarda;

- Cristina, la criada;

- Maese Nicolás, el barbero, amante de la criada;

- el estudiante Carraolano;

- Leoniso, compadre de Pancracio.

Al complicarse la trama, el duelo bilateral entre los esposos propio del relato se diluye algo, y el coro de figuras que resulta añade vivacidad y comicidad a la escena.

- El marido inadecuado. En Decameron VII.1 Gianni Lotteringhi, el simple y crédulo marido, se hace capitán de los laudeses, nada menos, que de Santa María Novella; y se vuelve experto en oraciones, canciones piadosas, lamentos, laudas «e cotali altri ciancioni» que le sirven para salvar su alma (cfr. 4-5), pero olvida su cuerpo, y descuida la vida conyugal. La beatería es un rasgo que Boccaccio ataca por la falta de inteligencia que implica, y por la ofensa que supone para la mujer inteligente que la padece; en este caso involucra además a los dominicos que desde Santa María Novella controlaban la vida religiosa de la ciudad.

La noche de los hechos, cuando desde la cama Gianni oye llamar a la puerta, trata de tranquilizar a doña Tessa, diciéndole que ya él había rezado un himno y una antífona al irse a acostar (cfr. 20). Ella urde un plan para salir del apuro y logra de paso castigar al marido adecuadamente, es decir, con las mismas armas y argumentos que él ha venido manejando contra ella. Es la técnica del "contrapasso» dantesco, que amolda el castigo a la falta cometida.

Así es que doña Tessa, con el amante al otro lado de la puerta, se levanta con Gianni a decir una "santa e buona orazione» para encantar al supuesto «fantasma». ${ }^{20}$ Como las oraciones del marido suplantaban al sexo, aquí

20. «Questo vocabolo serve in varie parti d'Italia per esprimere concetti diversi che hanno in comune solo l'idea del mostruoso e del pauroso». Cfr. Maria Pia Giardini, op. cit. p. 22. 
la oración alejará al amante, y el equívoco oraciones/sexo (que se repite en varios cuentos más) se afianza de forma lógica y natural. Gianni es burlado y castigado como merece su irracionalidad. Cuando al final de la oración su mujer le pide que colabore, él debe escupir. ${ }^{21}$

En el entremés, Pancracio, el necio marido, desde la primera escena dice creer en la magia; cuando Leonarda finge perder el sentido, él acude a unas palabras con poderes mágicos:

diréle una palabras que sé al oído, que tienen virtud para hacer volver de los desmayos.

Cervantes parodia no las oraciones, sino las prácticas esotéricas, las creencias en supercherías y en poderes mágicos; las "palabritas» de Pancracio desvelan su inclinación a la hechicería y anticipan su aceptación del conjuro final, que es el castigo también apropiado, réplica y contrapunto jocoso a la habilidad que él mismo se había atribuido. Como en muchos cuentos decameronianos, queda claro que la responsabilidad del adulterio recae en el marido; y los vectores que estructuran la acción de castigo se sitúan al inicio y se recuperan al final (cfr. I.4, «ayunos y vigilias» aludidos en el epígrafe 4 y retomados en 21).

Rasgo esencial del perfil de necio de Pancracio es su ciega confianza en su "honesta» mujer. Cuando esa noche regresa a casa y se la encuentra bien cerrada, Leonarda tarda en abrir mientras se ocultan los tres intrusos. La reacción de Pancracio coincide con la del marido de Peronella en análoga situación y con similar sistema expresivo; ${ }^{22}$ En ambos casos ellos acuden a la exclamación para dar gracias a Dios y al cielo por la mujer que les ha tocado en suerte:

O Iddio, lodato sia tu sempre, ché, benché tu m' abbi fatto povero, almeno m'hai tu consolato di buona e d'onesta giovane di moglie! (VII.2,11) ${ }^{23}$

Compadre: ¡Gran mujer! ¡De buena os ha dado el cielo señor compadre! Dadle gracias por ello.

Pancracio: Yo se las doy como puedo, y no como debo; no hay Lucrecia que se le llegue, ni Porcia que se le iguale; la honestidad y el recogimiento han hecho en ella su morada (p. 183).

Más adelante Pancracio insiste en «los recatos de mi Leonarda», «oh, recato inaudito de mujer prudente!» perfilando la parodia.

21. Como recuerda Maria Pia GiARDINI, según estas creencias mágicas, se escupe contra todo lo que parece que puede acarrear un mal (op. cit. p. 26).

22. En el film de Pier Paolo PASOLInI la necedad del marido de Peronella, y de otros personajes masculinos de su selección, se expresa magistralmente en su boca, en sus dientes, en su sonrisa, emblemas de su necedad. Es un rasgo de realismo de los más destacados del film.

23. Cito por la ed. de Vittore BRANCA, Turín: Einaudi, 1987. 
Pero Cervantes va más allá en el tratamiento del personaje-tipo: el necio marido pasa «de ignorante e ingenuo [...] a sospechoso y consciente del engaño al que ha sido sometido». ${ }^{24}$ De estereotipo pasa a ser un personaje moldeado por la acción de otros y por las circunstancias en las que logra de algún modo reaccionar. No obstante su gran recelo ante la presencia de tres hombres en su casa, sucumbe a su curiosidad hacia la magia. Pero al final, dando ya muestras de una cierta capacidad de reflexión, advierte que «averiguará» lo que hay detrás de los hechos de aquella memorable noche (cfr. p. 186-192).

- La esposa insatisfecha. Monna Tessa reacciona a la beatería y simplicidad del marido, ${ }^{25}$ y sustituye sus carencias afectivas y sexuales con el amor de Federico, «bello e fresco giovane» (6), buscando los medios para disfrutar. Otras protagonistas adúlteras del libro, o reaccionan a la beatería del marido (III.4), o a sus celos infundados (VII.4 y VII.5), o al marido anciano que la ha tocado en suerte (VII.8) o a su ambigüedad sexual (V.10).

De Leonarda no se dice si está enamorada, pero resulta claro su deseo de gozar de la vida que hay más allá de los rezos del marido y del recinto familiar. Es un personaje de dos caras, digna heredera del desparpajo de muchas de las heroinas decameronianas que refleja bien el carácter expeditivo de la mujer que se rebela al ver defraudadas sus expectativas de felicidad. En el clima de falsa paz familiar en el que Pancracio cree estar, Leonarda finge ante el marido hasta la caricatura; luego, en presencia del estudiante su actitud evolucionará:

- Reacciona con hipocresía en la despedida inicial, con mimos y ñoñería, ensartando apelativos cariñosos, tanto ella («bien mío», «descanso mío», «mi gusto», en p. 238-9), como el marido: «mi ángel», «lumbre destos ojos», «Leonarda mía», «vida mía» (p. 239-247). La retahíla de posesivos y apelativos por ambas partes desvela el fracaso de una relación conyugal de conveniencia donde todo es ficticio. Ángel Valbuena valoró esta escena como una parodia de la despedida íntima entre esposos.

- Cuando Pancracio desaparece de la casa Leonarda descubre su otra cara, se expresa con otro registro verbal y se hace dueña del espacio familiar, que dispone como escenario de la fiesta; la sumisión y respeto se vuelven desparpajo y descaro.

- Para ganar tiempo cuando Pancracio regresa de improviso y los dos amantes y el estudiante están ya en la casa, finge un excesivo celo para cerciorarse de que es el marido quien llama; en su interrogatorio acude a un motivo tradicional de gran fuerza expresiva y también presente en Decameron II.9,27

24. Cfr. Vicente Pérez de LeÓN, op. cit., p. 277.

25. Carlo DelCoRno, «Ironia/Parodia», en Lessico critico decameroniano, Torino: Bollati Boringhieri, 1995, p. 183, señala a Frate Puccio (de III.4) y a Gianni Lotteringhi como los beatos más esperpénticos de todo el libro. 
LEONARDA: ¿Qué señales tengo yo en uno de mis hombros?

PANCRACIO: En el izquierdo tienes un lunar del grandor de medio real, con tres cabellos como tres mil hebras de oro (p. 185).

Ella n'avea sotto la sinistra poppa, ciò che era un neo dintorno al quale erano alquanti peluzzi biondi come oro. (27).

El sugestivo motivo, ya de dominio común lo había banalizado Timoneda al reducirlo a "un lunar que (Finea) tenía en las espaldas» del que le cortan unos cabellos, sin precisar su color; ${ }^{26}$ Timoneda, como Cervantes, desplaza la ubicación estratégica del lunar a un lugar menos comprometedor; Cervantes mantiene la sugestión de los cabellos rubios, que Timoneda destruye.

- Como Pancracio, también Leonarda evoluciona ante la perturbación del estudiante en el escenario que ella había organizado. Así la mujer astuta y manipuladora pierde las riendas de los hechos y pasa a obedecer.

- Leonarda presentará una nueva cara de mujer temerosa e indecisa: teme que se descubran sus «liviandades» (p. 179); le asusta la posible aparición de los diablos, se siente incapaz de controlar la situación («librada sea yo de lo que librarme no sé» p. 187) y llega a confesar su temor: "aquí soy muerta», p.188. Así el tipo de mujer astuta y vencedora de la narrativa medieval cede paso a un perfil psicológico femenino más complejo.

- Cristina, la criada. Cómplice muy avispada de la doble vida de Leonarda, la sobrepasa en osadía, y toma iniciativas sin esperar la opinión de su señora; da órdenes encadenadas, que incluso riman («pues atúrese... cósase... amuélese... éntrese», p.180), habla con desparpajo y engasta dichos equívocos y alusiones obscenas con toda libertad. Su relación con el barbero refuerza el latente adulterio y el abandono a la sexualidad prohibida, extraconyugal, de la señora de la casa. Podría verse casi como una prolongación de Leonarda, pues dice lo que ésta no alcanza a expresar. Cristina alaba el porte del estudiante, y sugiere de forma velada el disfrute amoroso esa noche, también con él. Como Javier Huerta ha señalado, son más de una las «cristinas» de los entremeses cervantinos, todas respondonas y defensoras de su derecho a gozar. ${ }^{27}$

En este caso, además de ser un personaje lleno de vivacidad y de gracia, para canalizar el rechazo femenino a la sumisión que la sociedad imponía, esta Cristina es también un personaje que evoluciona en el vértigo de los acontecimientos, y acaba algo amedrentada y perpleja, como su señora,

26. Cfr. Joan Timoneda, El Patrañuelo, ed. de José Romera Castillo, cit. Patraña 15, p. 247. Cfr. también la nota de «Fuentes» elaborada por ROMERA, p. 253-254.

27. Javier Huerta CALVO, "Cristinas (en torno a las criadas de Cervantes)», en Luciano GarCía LORENZO (a cura di) La criada en el teatro español del siglo de oro, Madrid: Fundamentos, 2008, p. 95-112. 
expresando su temblor (p. 187) y sus dudas sobre la condición de los diablos. Al final pide que estos se queden a cenar, no lo ordena como era su costumbre, pero colabora de algún modo en el plan del estudiante y propicia el caos de la situación final.

Así pues, la evolución de los tres personajes canaliza la réplica de Cervantes hacia las fuentes y modelos tradicionales, y pone de manifiesto la gran novedad de la pieza teatral.

- El sacristán. Esta figura, en el teatro de la época, sustituye por razones de censura al cura o fraile de la tradición cuentística, acumulando sus vicios: es corrupto, juerguista, y amante de la buena mesa. ${ }^{28}$ A Reponce Leonarda le califica de generoso («muy cumplido»), quizás como contrapunto a su marido; cuando aparece en la casa hablando en un registro alto ella le critica. Y muestra otras habilidades en una escena memorable que precisa la acotación más larga de todas: «sale el sacristán con la sotana alzada y ceñida al cuerpo, danzando al son de su misma guitarra, y a cada cabriola, va diciendo estas palabras...» (p. 183).

También Reponce se pliega a la voluntad del estudiante, asume su papel de diablo (p. 189), recibe una buena reprimenda del estudiante al intentar blasfemar (cfr. p. 189) y acaba cantando un romance endiablado, de registro bajo y cargado de alusiones sexuales, religiosas y sociales difíciles de interpretar. Tras la magia, el sacristán evoluciona a "sacridiablo», y en una técnica casi de "contrapasso» asume él el papel dominante de diablo, ya que el barbero queda en segundo término.

- El barbero, completa la pareja de amantes invitados a la transgresión; a dúo amenizarán con sus canciones y bailes la velada final. En la emisión del romance el barbero repite el estribillo: "La cueva de Salamanca».

El principal objetivo de una noche de buena comida y sexo del modelo boccacciano y tradicional, por razones escénicas y de censura, se diluye, reduciéndose a la abundante cena, a la música y al baile atrevido, tan del gusto del teatro de la época; los entremeses, como la comedia, suelen acabar en fiesta. Si el amor extraconyugal no entra en el teatro de Cervantes, aquí se alude a él como algo previsto y que queda latente, como plan que ha fracasado pero que se supone que se volverá a intentar.

- El estudiante. Aunque para darle un barniz castizo, Cervantes le hace salmantino, ${ }^{29}$ la figura del nigromante ficticio pertenece al repertorio cómico internacional, que el narrador transforma y enriquece alejándole de su carácter tipificado.

Carraolano va desvelando a cada paso nuevas facetas de su sorprendente personalidad; primero se presenta como un pobre en busca de cobijo esa 
noche, luego dice ser graduado en bachiller por Salamanca, luego confiesa dominar la magia aprendida en la cueva de Salamanca, un saber prohibido por la Iglesia y castigado por la Inquisición, ${ }^{30}$ que dice poner en práctica esa noche para disfrutar de la cena prometida y de paso resolver el apuro familiar que le es más ajeno. Él «defiende una filosofía de la vida en la que la facilidad de manipular a los semejantes es fundamental para la supervivencia en una sociedad en la que todavía pervive la creencia y el respeto a lo sobrenatural». ${ }^{31}$

Como Boccaccio se burla de los incautos que creen en la magia que el escolar Rinieri de Decameron VIII.7, dice haber aprendido en la prestigiosa Universidad de París, Cervantes atacaría tanto el prestigio de los estudios en la Universidad de Salamanca (al final, p. 191, se equiparan los poetas a los diablos) como la supuesta magia de la cueva. El motivo de la tradición popular hispánica de la cueva de Salamanca y su esotérico saber ha sido bien estudiado en su historia y posible significado. ${ }^{32}$

En la trama del entremés el motivo se maneja para resolver la gran tensión que se ha creado en la casa con las tres presencias masculinas que multiplican la posibilidad de adulterio. El estudiante, el más ajeno a la vida familiar, con gran capacidad de transgresión toma las riendas de la acción ante Pancracio y Leonarda y ante todos los demás.

Con atrevimiento, con osadía, con prepotencia, va ganando terreno hasta plantarle cara a todos: «voto a...de no irme de esta casa, si todo el mundo me lo manda» (p. 181).

Se niega a esconderse, como las mujeres le mandan («escóndanse ellos donde quisieren", p. 184), y acaba desvelando sin tapujos el plan que el marido ha desbaratado: «hubiera cenado mejor y tenido más blanda y menos peligrosa cama» (p. 186).

La novedad del texto cervantino reside en la enorme modernidad del «recurso de introducir en el espacio de un hogar de un extraño que atenta con quebrar la aparente armonía de un matrimonio caracterizado por el deseo no consumado de la malcasada esposa y la simpleza y mezquindad del marido». ${ }^{33}$ Con Carraolano en la casa se instala la sorpresa, lo imprevisible y excepcional. Él se burla de la institución del matrimonio, del código del honor, de las normas religiosas, de la Inquisición. Controla al resto de los personajes, para, reivindicar con gran cinismo sólo algo tan material como la cena.

30. Como ha recordado Miguel Ángel Pérez Priego, ya desde 1376 los libros de conjuros y de magia se mandaban quemar por la Inquisición. Cfr. Miguel Ángel PérEZ PRIEGO, «El conjuro de Celestina» en Pilar CARRASCO (a cura di) El mundo como contienda. Estudios sobre la Celestina, Analecta Malacitana, Anejo XXI, p. 80.

31. Vicente PÉREZ de LEÓN, op. cit., p. 237.

32. Manuel García BlanCO, «El tema de la Cueva de Salamanca y el entremés cervantino de este título", Anales Cervantinos, 1, 1951, p. 71-109.

33. Vicente PÉREZ de LEÓN, op.cit. p. 243. 
- Los supuestos demonios. El estudiante urde la farsa de hacer aparecer a los amantes como demonios, ante el marido, de un modo análogo a cómo la protagonista de Decameron VII.1 identifica a su amante delante del marido con «la fantasima» o supuesto ser maligno de las creencias y supersticiones del pueblo, ser fantástico que no se sabe muy bien qué es.

En Decameron IV.2 frate Alberto se había servido también del supuesto cuerpo del arcángel San Gabriel para engañar a doña Lisetta, con un juego magistral entre el cuerpo y el alma. Bien acudiendo al ángel o al demonio, se trata de un hilarante pretexto para encubrir, con lo extrahumano, la realización de algo tan humano como el deseo carnal.

En el entremés los diablos asumen la personificación del mal, alimentada por las prácticas folclóricas y las creencias religiosas. La ingeniosa invención está además pensada para provocar un fuerte impacto en el momento de la representación; es sabido que la presencia del diablo en la escena medieval aseguraba el disfrute del espectador.

La curiosidad que suscitan provoca un afán descriptivo-valorativo que perfila un hilarante catálogo de rasgos, entre humanos y sobrenaturales. Cristina y el barbero, ante la supuesta aparición infernal, se preguntan si son bautizados o no, cuestionando su adscripción religiosa; si comen o no, cuestionando su humanidad; se les califica en el plano social como «bien criados y corteses», "honrados y muy hombres de bien»; y tras el romance en boca de los diablos, se constata que «todos los poetas son diablos» (p. 190-191) para culminar un análisis que va de lo corporal a lo social, a lo religioso y a lo intelectual. El mecanismo que aplica Cervantes es más completo y elaborado que el juego alma/cuerpo del relato de fra Alberto, centrado sobre todo en lo sexual y que, no obstante, ofrecía a la tradición posterior un procedimiento magistral.

Cervantes se aleja de toda esta tradición en el momento en que el estudiante les da órdenes a los propios diablos, a los que controla con dureza y decisión. Culmina así el proceso de evolución que el escritor activa, perfilando más aún la novedad del estudiante como personaje singular.

\subsection{Comida y sexo en el Decameron}

En más de una quincena de cuentos decameronianos se unen el placer de la mesa y el placer del sexo como dos momentos del disfrute liberador de los sentidos y de la subversión. Esos momentos, además, sirven de contrapunto a la situación tantas veces repetida de las refinadas y exquisitas comidas descritas en el marco del libro, dentro del ritual social cortés y elegíaco del mismo; se refuerza así la idea implícita de que los diez jóvenes logran el equilibrio y el control en sus comidas ordenadas y honestas, sin dejarse contaminar por lo narrado tantas veces en los cuentos.

En relatos de registro cómico es usual que la mujer se esmere en la comida que le prepara al amante, preludio de un buen trato en la intimidad que le seguirá al banquete. Véase II.2, III.4, V.10, VII.1, VIII.10, y muchos más. 
Pero es en VII.1, el citado cuento de Gianni Lotteringhi, donde, frente a la descarada frugalidad de la cena que donna Tessa le da al marido que llega de improviso, ("un poco di carne salata che da parte aveva fatta lessare»), se insiste cuatro veces en la cena preparada para disfrutar con el amante:

- primero se precisa cómo éste, Federico di Neri Pegolotti, en su primer encuentro amoroso con doña Tessa, «a grande agio e con molto piacere cenò e albergò con la donna» (parágrafo 8);

- luego, con mayor detalle se describe el menú que ella esa noche había preparado para ambos («avendo ella fatti cuocere due grossi capponi», 13);

- después se repiten los detalles al darle orden a su criada de que lo lleve todo al jardín, para que el marido no lo vea y Gianni lo pueda disfrutar («E alla fante fece portare in una tovagliola bianca i due capponi lessi e molte uova fresche e un fiasco di buon vino", 13).

- por último en una parte del mensaje cifrado del conjuro se alude a algunos componentes de la cena de forma encubierta, reforzando la parodia: «troverai unto bisunto e cento cacherelli della gallina mia: pon bocca al fiasco...». Así Federico entiende que la cena está en el jardín, y ésta al menos le compensará el frustrado encuentro amoroso.

Los componentes de la cena son un protagonista más de los hechos en el cuento; la complacencia en los capones, los huevos, el buen vino, son elementos clave de la fuerza narrativa de la trama y de su comicidad.

El traductor anónimo de la versión castellana antigua respeta fielmente sus componentes, su posición y su repetición: «et a la moça mandó que levasse en una tovaia muy blanca embueltos los dos capones et muchos huevos fritos e un barril de buen vino et que lo levasse a su jardín». ${ }^{34}$

\subsection{La comida en el entremés}

Vicente Pérez de León ha señalado varias veces cómo en el entremés se refleja la imposibilidad de resolver los conflictos humanos en la época. Y apunta la sugestiva tesis del «desequilibrio humano que es fundamental para entender el papel de los protagonistas» ${ }^{35}$ remitiendo a la destemplanza de que hablara Huarte de San Juan.

De acuerdo con ello podría decirse que la frustración en los conflictos esenciales de la época como honor/deshonor, o libertad/represión, encontrarían en la comida el único medio de consuelo posible a la destemplanza. Así se expresa en el entremés, donde la buena cena todo lo resuelve, al menos por esa noche.

34. Cito por el ejemplar de la edición de Sevilla, 1496, conservado en la Bibliothèque Royale de Belgique (inc. B.399), folio $139 \mathrm{v}$.

35. Vicente PÉREZ de LEÓn, op. cit., p. 109 y 113. 


\subsection{El conjuro, motivo esencial}

- En el Decameron. En VII.1 la mujer de Gianni Lotteringhi conjura con una oración al fantasma, o espantajo que está al otro lado de la puerta. Tanto aquí como en el entremés la estrategia consiste en convertir al amante en un ser sobrenatural, fantasma o diablos.

Un conjuro, sintetiza Pedrosa, es:

Un discurso que una persona dirige a un personaje sagrado o demoníaco con el objeto de exigirle o de obligarle a la concesión de un favor mágico, que pude ser, aunque no siempre, moralmente negativo o perjudicial para otras personas. El conjuro suele tener un tono imperativo o autoritario [...] y refleja creencias más apegadas a lo mágico y que se sitúan en los márgenes o fuera de la norma impuesta por la religión dominante. ${ }^{36}$

La parodia boccacciana afecta tanto a la superstición religiosa como a la magia, prácticas que el escritor ataca con saña en numerosos relatos del libro por la irracionalidad y desmesura que comportan.

Es monna Tessa ("savia e avveduta molto») quien la desencadena, vengándose de la beatería del marido, concentrado en sus obras piadosas y en la oración (cfr. el parágrafo 5). Para ello dice acudir a la magia del conjuro aprendido de una anciana ermitaña muy santa del lugar; el instrumento de la santa oración, la procedencia de la misma y la ayuda que Tessa le pide al marido al pronunciar el conjuro para alejar al intruso, convencen plenamente al marido, que termina escupiendo como se le ordena.

Reproduzco el conjuro con una hipotética y experimental presentación en versos, que no tiene base filológica pero que subraya mejor las asonancias del párrafo:

Fantasima, fantasima

che di notte vai,

a coda ritta ci venisti,

a coda ritta te n'andrai:

va nell'orto,

a piè del pesco grosso troverai

unto bisunto

e cento cacherelli della gallina mia:

pon bocca al fiasco e vatti via,

e non far mal né a me né a Gianni mio (27).

Doña Tessa, con expresiones cifradas, mezcla las alusiones obscenas referidas al sexo y a los componentes de la cena. Con apariencia de mensaje de conjuro mágico para ahuyentar un mal, simulando sus fórmulas imprecatorias,

36. José Manuel Pedrosa, Entre la magia y la religión: oraciones, conjuros, ensalmos. Oiartzun: Sendoa Editorial, 2000, p. 10. Y remito de nuevo al estudio de Pedrosa citado en nota 3 donde el conjuro se valora como elemento integrante de la sólida red de coincidencias entre el entremés y el cuento VII,1 que Pedrosa considera «más que notables». 
Tessa le informa al amante dónde tiene la comida, y le ordena marcharse, porque el marido está con ella. Para confirmarlo se hace acompañar por él.

La parodia estriba en manejar los rasgos canónicos del género de los conjuros y sus fórmulas apotropaicas que el saber popular empleaba para aplacar las tormentas, o hacer desaparecer males o enfermedades colectivas. ${ }^{37}$ Aquí se esgrime para algo nimio, en una escena de vida cotidiana y sólo en interés personal de Tessa para salir del apuro conyugal.

La oración se moldea sobre la técnica del conjuro tradicional, que la muy antigua tradición cultural transmite casi siempre con análoga fórmula: vocativo inicial, versificación aproximativa, ritmo muy pausado, rimas esporádicas y asonancias, algunos octosílabos localizables, fórmulas verbales características, lenguaje críptico y la prescriptiva orden apremiante e intimidatoria al final. ${ }^{38}$

Además monna Tessa inventa que el marido intervenga también, y le hace escupir como colofón hilarante y humillante, de forma que el amante, al otro lado de la puerta, añade que debería escupir «los dientes». Este motivo final desaparece en la traducción castellana antigua, que incorpora la variante de que el marido hable alto, para confirmar su presencia. Reproduzco el conjuro, por lo demás bien resuelto por el traductor, (acentúo, puntúo y acudo de nuevo a la hipotética forma en versos):

Fantasma, fantasma,

Que de noche vas,

Rabialçada aquí veniste

Rabienroscada assí te tornarás;

Vete al jardín

al pie del friscal gruesso

Et fallarás unas tovaias

Et muchos huevos de mis gallinas;

Pon la boca en el barril

Et vete en buena hora

Et non fagas mal

$\mathrm{Ni}$ a mí ni a Juan mi marido. ${ }^{39}$

Al final del cuento decameroniano se alude, por añadidura, a dos versiones de la oración, ambas existentes, para que el receptor elija. Así se refuerza la presencia del hábito de las supercherías que se quiere parodiar.

- El conjuro del Laberinto de Fortuna. Se ha venido señalando la deuda del conjuro del entremés cervantino con unos versos solemnes del poema de Mena (estrofas CCXLVI y siguientes) donde la maga invoca a Plutón y a

37. Cfr. el texto de José Manuel Pedrosa, op. cit., p. 10-86.

38. Francesco BRUNI, Boccaccio. Linvenzione della letteratura mezzana, Bologna: Il Mulino, 1990 , p. 374.

39. Folio 139 v. Edición de Sevilla, 1496, cit. 
Proserpina, siguiendo el modelo de un episodio de La Farsalia. En coplas de arte mayor, «el verso heroico que convenía mejor al estilo sublime y a su contenido grave» ${ }^{40}$ y en un episodio de especial tensión de esa poética de lo sublime, a lo largo de una serie de estrofas, tras el vocativo inicial, se reiteran las peticiones, seguidas de amenazas conminatorias, dirigidas a Cerbero y a Caronte. La conexión entre ambos textos se confirma con el cotejo de los mismos. Subrayo aquí el vocativo inicial, las órdenes, las amenazas apremiantes, que son los mecanismos comunes que permiten dimensionar mejor la parodia cervantina:

Dale salida, velloso Cerbero, por la tu triste trifauce garganta, pues su tardança non ha de ser tanta $e$ dale pasada tú, vil marinero.

¿Pues ya qué fazedes?:a quándo os espero?

Guardad, no me ensañe, si non otra vez

Faré desçendervos allá por juez

A aquél que vos truxo ligado primero

$[\ldots]$

si non obedesces la mi ordenança,

la cara que muestras a los del infierno

faré que demuestres al cielo superno

$[\ldots]$

obedeçedme, si non llamaré

a Demogorgón... ${ }^{41}$

- El conjuro del entremés. Cervantes acude al conjuro en El trato de Argel, en La Numancia, y en los dos entremeses citados. Al uso del dodecasílabo que ha sido señalado como principal razón para conectar ambos textos, hay que añadir además el manejo de la técnica expresiva y alocutiva del conjuro. ${ }^{42}$ Reproduzco los versos cervantinos subrayando los mecanismos expresivos:

Vosotros, mezquinos, que en la carbonera

hallastes amparo a vuestra desgracia, salid, y en los hombros, con priesa y con gracia, sacad la canasta de la fiambrera;

40. Cfr. Miguel Ángel Pérez Priego, «Introducción» a Juan de Mena, Laberinto de Fortuna, Córdoba: Fundación José Manuel Lara, 2003, p. XXXVII.

41. Ed. cit., estrofas CCXLVIII y ss., p. 137-139.

42. Cfr. Pilar Palomo, ed. Ávila: La Muralla, 1967, p. 195; Eugenio Asensio, ed. Madrid, Castalia, 1970, p. 196, nota 11; Nicholas SPADACCHINI, ed. Madrid: Cátedra, 1998, p. 250 , n. 60 . 
no me incitéis a que de otra manera

más dura os conjure. Salid. ¿qué esperáis?

Mirad que si a dicha el salir rehusáis,

tendrá mal suceso mi nueva quimera. (p. 188).

Sugiero valorar las analogías con el conjuro de Decameron VII, 1 no sólo en su sistema expresivo, que sigue en buena parte la estructura del género, sino en la cadena de circunstancias argumentales que les rodean:

1. la situación inicial análoga: marido que regresa de improviso y amante que cuenta con una noche de comida abundante y disfrute sexual;

2. alusión, en el conjuro, al desvanecerse de las perspectivas de una noche de amor como se había previsto;

3. alusión también a la comida, con instrucciones para aprovecharla;

4. mensaje cifrado al amante que ambos conjuros encierran con pautas de cómo salir del paso;

5. la fórmula del vocativo inicial más oración de relativo más orden conminatoria se da en ambos casos.

Otro paralelismo podría darse en el mecanismo paródico común de ambos autores, manejado con similar destreza en la hipotética conversión de los amantes en diablos y la supuesta conversión de Frate Alberto en IV.2 en el arcángel san Gabriel con el cuerpo de los amantes; en el entremés el estudiante promete sacar de la carbonera dos diablos con el cuerpo del barbero y el sacristán; frate Alberto le explica a doña Lisetta que hará que el ángel que la va a visitar adopte su propio cuerpo; la conversión en ángel o diablo funciona en ambos casos como mecanismo paródico de gran eficacia.

En el entremés cervantino no es Leonarda quien inventa la estratagema del conjuro, como Tessa en Decameron VII.1, sino que lo hace el estudiante para hacer salir a la pareja, y no tanto resolver la situación comprometida para las dos mujeres, sino, sobre todo, lograr él cenar bien esa noche.

En el final del entremés el estudiante inserta otra orden a modo de recomendación en tono de mensaje cifrado para ratificar el cambio de planes para esa noche, donde destaca el tratamiento con el que él se dirige a los diablos, y cómo, salvo atentar contra los preceptos religiosos (el pecado sería blasfemar), casi todo está permitido en esa noche:

Demonico, demonico, aquí no venimos a hacer pecados mortales, sino a pasar una hora de pasatiempo y cenar e irnos con Cristo (p. 252).

En cambio Pancracio, dirigiéndose a los visitantes inesperados con el ceremonioso «señores demonios», atemorizado, pregunta si los diablos comen, a lo que el barbero responde:

Barbero: Sí comen algunos, pero no todos, y nosotros somos de los que comen (p. 189). 
La entonación y el cinismo esgrimidos podrían recordar la perplejidad y el tono con que madonna Agnesa le pregunta a Frate Rinaldo si los frailes hacen «esas cosas» y a la resuelta respuesta del fraile (VII.3, 14-5).

También Cristina aporta sus apreciaciones sobre los demonios para amenizar la escena, con una cadena de calificativos referidos a los mismos, como Boccaccio había ya fijado; véanse fórmulas como «santa e buona orazione» del muy citado cuento VII.1,3. ${ }^{43}$

- Sexo y magia en el entremés. Se ha señalado repetidamente que resulta desconcertante la unión de magia y sexo en el entremés. No lo es para el lector del Decameron habituado a la estrecha vinculación entre ambos elementos en varios cuentos del libro, desde el momento en que la magia resuelve a menudo una situación matrimonial muy comprometida, y además, casi siempre en esos mismos relatos el adulterio está propiciado por la escasa atención que un marido beato y supersticioso le presta a su joven esposa, que se vengará de él.

Cervantes parece excluir el sexo del plan de fiesta de esa noche de aquelarre y buena cena. Queda latente la idea, la posibilidad. Primero estaba prevista en el plan de esa noche para Leonarda y Cristina con el sacristán y el barbero; la presencia del estudiante aumenta las posibilidades de tal fiesta, desde el momento en que ambas mujeres dicen veladamente desearle, y pactan con él para que guarde el secreto de lo que allí verá, le insinúan la posibilidad de participar con ellos, y le prometen una buena cena.

El plan amoroso se frustra, y el estudiante, cuando ya lo controla todo sólo él, deja bien claro lo que resta por hacer: "pasar una hora de pasatiempo y cenar, y irnos con Cristo" (p. 189).

Ha sido señalado que Cervantes «transforma un entremés de adulterio y deshonra en una celebración carnavalesca que incluye una gran comida que despide deseos y atracciones carnales entre personajes»; 44 también que «el adulterio se lleva a cabo simbólica y limitadamente en una comilona carnavalesca y lúdica»; ${ }^{45}$ Cervantes acude a una muy sutil ambigüedad para superar unos modelos que le eran inservibles. Los significados se superponen, se enriquecen, y proyectan el texto a un mundo de desequilibrio que se ha visto como impropio ya del Renacimiento.

Puede ser que se deje a la intuición o arbitrio del lector o espectador averiguar en qué puede consistir la hora de pasatiempo que menciona el estudiante. La ambigüedad es igualmente significativa y nos sitúa ante un dominio de lo literario que se hace más evidente y desconcertante cuanto más se analiza. 


\subsection{Equivocos sexuales}

La serie de equívocos sexuales del final del entremés recuerda a la analogía oraciones/actividad sexual que está en la base de la comicidad de varios cuentos decameronianos; en el final de VII.1,8 se dice que monna Tessa le enseña a su amado Federigo «da sei delle laude» de las del marido beato; con análogo doble sentido equívoco el socio de Frate Rinaldo en VII.3,23 le enseña el "padrenuestro» a la criada de madonna Agnesa, mientras ésta y el fraile «encantaban a las lombrices».

Cervantes, no implica en su parodia ni las oraciones ni lo sagrado, pero poniendo aquí en boca del sacristán el motivo del aprendizaje, acude a la analogía baile/sexo para concluir festivamente:

Sacristán: Con cuatro mudanzas que yo le enseñase a vuesa merced [se refiere a Leonarda] cada día, en una semana, saldría única en el baile: que sé que le falta bien poco (p. 192).

El doble sentido baile-actividad sexual se maneja de modo equivalente a cómo en el Decameron se hablaba de oraciones, como broche a la comicidad final.

\section{Conclusión}

Las coincidencias de temas y técnicas con los modelos decameronianos que he ido señalando avalarían o bien el posible almacenamiento, en la memoria acumulativa de Cervantes, de la lectura del libro de Boccaccio, o bien el manejo de los textos de los «novellieri» y del teatro que los heredó.

Estamos en muchos casos ante actitudes tipificadas de la conducta humana. Por ello, para poder sostener el empleo de modelos literarios puede ser útil valorar, sobre todo, el uso de técnicas expresivas y compositivas superpuestas a lo estrictamente argumental.

Proseguir en esta línea de trabajo puede aclarar desde otras perspectivas algunos de los mecanismos constructivos de los entremeses de Cervantes y valorar mejor su gran innovación en la tradición cómica europea. 